Check for updates

Cite this: RSC Adv., 2017, 7, 31342

\title{
Design and synthesis of graphene/activated carbon/polypyrrole flexible supercapacitor electrodes
}

\begin{abstract}
Lanshu Xu, (D) Mengying Jia, Yue Li, (D) Shifeng Zhang (D) and Xiaojuan Jin*
A ternary composite of graphene/activated carbon/polypyrrole (GN/AC/PPy) used as an electrode active material for supercapacitors has been synthesized via vacuum filtration and anodic constant current deposition methods. The ACs sandwiched between GN sheets can be used as flexible substrates for PPy nanoparticles, and the microscopic morphologies and electrochemical performances of GN/AC/PPy electrodes were synthesized and designed through regulating different deposition current densities and deposition times. The GN/AC/PPy $15-200$ s electrode exhibits a maximum areal specific capacitance of 906 $\mathrm{mF} \mathrm{cm}{ }^{-2}$ with a PPy loading mass of $2.75 \mathrm{mg} \mathrm{cm}^{-2}$ (specific capacitance of $178 \mathrm{~F} \mathrm{~g}^{-1}$ ) at a current density of $0.5 \mathrm{~mA} \mathrm{~cm}^{-2}$. Its capacitance retention still remained at $64.4 \%$ after 5000 charge-discharge cycles and $83.6 \%$ after 500 stretching-bending cycles at a current density of $3 \mathrm{~mA} \mathrm{~cm}^{-2}$. The flexible, free-standing and binder-free GN/AC/PPy electrodes have a broad prospect in flexible energy storage devices.
\end{abstract}

Received 24th April 2017

Accepted 14th June 2017

DOI: $10.1039 / \mathrm{c} 7 \mathrm{ra04566b}$

rsc.li/rsc-advances

a simple, convenient and non-polluting without the need of any oxidant or reductant. The obtained composites can be used as electrode material and electrochemically measured directly. ${ }^{18}$

Flexible substrates, such as stainless steel wire meshes, ${ }^{19-21}$ cotton textile, ${ }^{22}$ carbon cloth $^{23-25}$ and other carbon-based paper, have been widely used to construct flexible electrodes. Activated carbons (ACs), as the earliest and the most widely application of electrode materials, possess the characteristics of porous carbon structure, easy processability, low-price, renewable, environmental friendliness, higher specific surface area and electrochemical stability. ${ }^{26,27}$ However, powder-like ACs are difficult to directly handle as flexible electrode materials, binders (poly(vinylidene fluoride) (PVDF) or poly(tetrafluoroethylene) (PTFE)) are always needed in composites. ${ }^{28,29}$ Twodimension (2D) graphene (GN) sheets have the advantages of high carrier mobility, excellent mechanical flexibility and selfassembly property. ${ }^{30,31}$ Thus, the $2 \mathrm{D}$ GN sheets can serve as an ideal adhesive and supporter for ACs, making ACs apply to flexible electrode materials potentially. The combination of GN sheets and ACs can form a free-standing and flexible substrate without any binder, which is helpful for mechanical properties of flexible electrodes. ${ }^{32}$ Meanwhile, the synergistic effects of excellent mechanical flexibility GN sheets, high conductive ACs and pseudocapacitive PPy have contribution to the high electrochemical performance of flexible electrodes.

Herein, flexible GN/AC/PPy electrodes were successfully synthesized by two-step process. The as-constructed GN/AC films were fabricated by vacuum filtration method and used as flexible substrates for PPy electro-deposition. The microscopic morphologies and electrochemical performances of GN/ AC/PPy flexible electrodes were designed and evaluated through

MOE Engineering Research Center of Forestry Biomass Materials and Bioenergy, Beijing Key Laboratory of Lignocellulosic Chemistry, Beijing Forestry University, Beijing 100083, China. E-mail: jxj0322@163.com; Tel: +86-010-62337178 
regulating different deposition current densities and deposition times via anodic constant current deposition method. The microstructure characterization and chemical compositions of the as-prepared GN/AC/PPy electrode were characterized by scanning electron microscopy (SEM), Brunauer-Emmett-Teller (BET), Fourier transform infrared spectroscopy (FTIR) and Raman spectra. Moreover, the electrochemical properties were studied through cyclic voltammetry (CV), galvanostatic chargedischarge (GCD), and electrochemical impedance spectroscopy (EIS) tests in a three-electrode configuration in $1 \mathrm{M} \mathrm{H}_{2} \mathrm{SO}_{4}$ aqueous electrolyte. As expected, the flexible GN/AC/PPy electrode exhibits a high areal specific capacitance of $906 \mathrm{mF} \mathrm{cm}^{-2}$ with PPy loading mass of $2.75 \mathrm{mg} \mathrm{cm} \mathrm{cm}^{-2}$ (mass specific capacitance of $178 \mathrm{~F} \mathrm{~g}^{-1}$ ), which is higher than pure GN and GN/AC electrode materials. The high electrochemical properties, excellent mechanical flexibility, free-standing and binder-free GN/AC/PPy electrode is a promising electrode material for flexible supercapacitors.

\section{Experimental}

\subsection{Synthesis GN/AC/PPy electrodes}

Ultrathin graphene oxide (GO) was obtained by chemical treatment of exfoliated graphite powders according to the modified Hummers' method ${ }^{33,34}$ and carefully diluted into $2 \mathrm{mg} \mathrm{mL}^{-1}$ using deionized water. AC materials derived from waste fiberboard (contains $12 \mathrm{wt} \%$ urea-formaldehyde resin adhesive) were carbonized and activated in high temperature furnace. ${ }^{35}$ Then, AC powders were dispersed in $N, N$-dimethylformamide (DMF) to produce a homogeneous dispersion of $0.5 \mathrm{mg} \mathrm{mL}^{-1}$. The GN/AC composite films with a mass ratio of $1: 2$ were constructed by vacuum filtration method. Firstly, GO suspension $(5 \mathrm{~mL})$ was mixed with AC dispersion $(40 \mathrm{~mL})$ and added DMF $(5 \mathrm{~mL})$ into Erlenmeyer flask. ${ }^{36}$ The mixtures were under ultrasonic vibration for $2 \mathrm{~h}$ to form a homogeneous suspension. Secondly, a small quantity of $80 \%$ hydrazine hydrate was added in Erlenmeyer flask to reduce GO. After being vigorously shaken, the Erlenmeyer flask was put in a water bath $\left(\sim 95^{\circ} \mathrm{C}\right)$ for $3 \mathrm{~h}$. Then, the mixtures were filtered via vacuum filtration using $0.45 \mu \mathrm{m}$ organic microporous membrane to form a GN/AC flexible substrate. Finally, threeelectrode system was used for polymerization and a GN/AC film of size $1 \times 2 \mathrm{~cm}^{2}$ was used as working electrode. An electrolyte solution containing $0.1 \mathrm{M}$ pyrrole and $0.5 \mathrm{M} \mathrm{H}_{2} \mathrm{SO}_{4}$ was used for electro-deposition of PPy. Polymerization was carried out at different deposition current densities of 5, 10, 15 and $20 \mathrm{~mA}$ $\mathrm{cm}^{-2}$ with a same deposition time of $200 \mathrm{~s}$ (namely GN/AC/PPy ${ }^{-}$ $200 \mathrm{~s}, \mathrm{GN} / \mathrm{AC} / \mathrm{PPy}_{10} 0^{-200} \mathrm{~s}, \mathrm{GN} / \mathrm{AC} / \mathrm{PPy}_{15}-200 \mathrm{~s}$ and $\mathrm{GN} / \mathrm{AC}^{-} \mathrm{PPy}_{20^{-}}$ $200 \mathrm{~s}$ ) and different deposition times of 100, 200 and $300 \mathrm{~s}$ with a same deposition current density of $15 \mathrm{~mA} \mathrm{~cm}{ }^{-2}$ (namely GN/ $\mathrm{AC} / \mathrm{PPy}_{15}-100 \mathrm{~s}, \mathrm{GN} / \mathrm{AC} / \mathrm{PPy}_{15}-200 \mathrm{~s}$ and $\left.\mathrm{GN} / \mathrm{AC} / \mathrm{PPy}_{15}-300 \mathrm{~s}\right)$. The pure GN and GN/AC composite film were used as blank samples and processed in the similar method.

\subsection{Characterizations}

The microscopic morphologies of the composites were characterized by scanning electron microscope (SEM, JEOL JSM-7001F).
Brunauer-Emmett-Teller (BET) surface area was measured via $\mathrm{N}_{2}$ adsorption/desorption using a Micromeritics ASAP 2010 analyzer. The chemical structures of the composites were analyzed by Fourier transform infrared spectroscopy analyzer (FTIR, PerkinElmer Spectrum 100 Model). Raman spectra were collected by a LabRAM HR Evolution Raman spectroscopy using a $532 \mathrm{~nm}$ laser source. All samples were cut into $1 \times 1 \mathrm{~cm}^{2}$ slice and all electrochemical performances were investigated using $1 \mathrm{M} \mathrm{H}_{2} \mathrm{SO}_{4}$ aqueous solution as electrolyte. Cyclic voltammetry (CV), galvanostatic charge/discharge (GCD) and electrochemical impedance spectroscopy (EIS) curves were tested on a CHI 660D electrochemical workstation in three-electrode system.

\section{Results and discussion}

\subsection{Morphology and structure characterization}

The strategy of designing flexible and free-standing GN/AC/PPy electrode is illustrated in Fig. 1. The 2D GN sheets have a good mechanical flexibility, which can be served as ideal binder and supporter. AC particles were bonded together with GN sheets by a facile vacuum filtration process. As shown in Fig. 1, the AC particles sandwiched between GN sheets, expanding the layer spacing of GNs to some extent. The obtained GN/AC flexible films are directly used as the working electrode and pyrrole monomers are electrodeposited on the surface of GN/AC flexible films. The morphology of PPy in the flexible substrate can be controlled by electro-deposition current densities and reaction times. Moreover, the flexible GN/AC/PPy electrodes can be bended arbitrary.

Fig. 2 shows SEM images of all GN/AC/PPy electrode materials. From Fig. 2a, we can obviously see that $2 \mathrm{D}$ GN sheets are regarded as adhesive to connected power-like ACs, forming a binderfree and flexible substrate. Under a small deposition current density $\left(5 \mathrm{~mA} \mathrm{~cm}^{-2}\right)$, pyrrole monomers begin to generate PPy and randomly distribute throughout the surface layer of porous film. Along with the increase of the current density, the grain size of PPy gradually gets bigger and bigger. As shown in Fig. $2 \mathrm{~b}$ and c, PPy further agglomerates and grows into a coral-like shape, which is formed by the accumulation of microspheres (seen the insert image in Fig. 2c). The coral-like PPy is rougher, thinner and more stretch, providing lager specific surface area and greatly enhancing the transmission capacity of conductive ions. With the further increase of deposition current density (Fig. 2d),

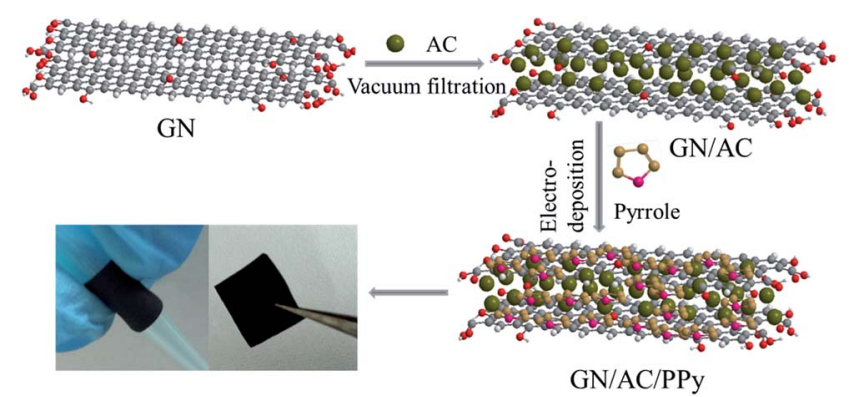

Fig. 1 Schematic illustration of the synthesis process of GN/AC/PPy film electrode. 

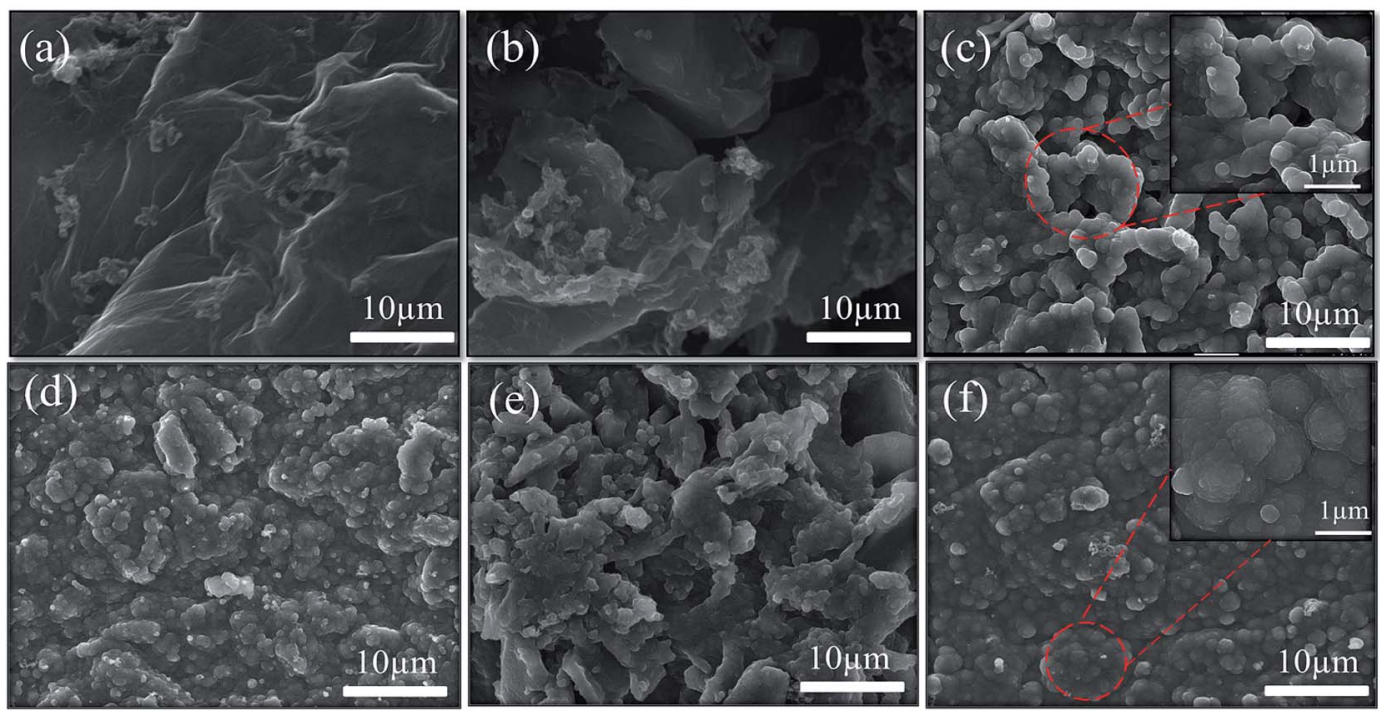

Fig. 2 GN/AC/PPy electrode materials under different electro-deposition conditions: (a) GN/AC/PPy $5-200$ s; (b) GN/AC/PPy $10-200$ s; (c) GN/ $\mathrm{AC} / \mathrm{PPy}_{15}-200 \mathrm{~s}$; (d) GN/AC/PPy $20-200 \mathrm{~s}$; (e) GN/AC/PPy $15-100$ s; (f) GN/AC/PPy $15-300 \mathrm{~s}$.

rod-like PPy film with dense layer is formed at a higher deposition current density of $20 \mathrm{~mA} \mathrm{~cm}{ }^{-2}$, which greatly reduces the specific surface area of the electrode material. Under the optimal deposition current density $\left(15 \mathrm{~mA} \mathrm{~cm}^{-2}\right)$, the different deposition times have been characterized. As shown in Fig. 2e, a rather rough surface with raised microspheres is formed in $\mathrm{GN} / \mathrm{AC} /$ $\mathrm{PPy}_{15}-100$ s electrode material, preparing for the growth of corallike PPy. As for GN/AC/PPy $15^{-300 ~ s, ~ F i g . ~ 2 f ~ s h o w s ~ a ~ d e n s e ~ a n d ~}$ thick PPy layer has coated on the GN/AC film due to the continued growth and agglomeration of PPy microspheres.
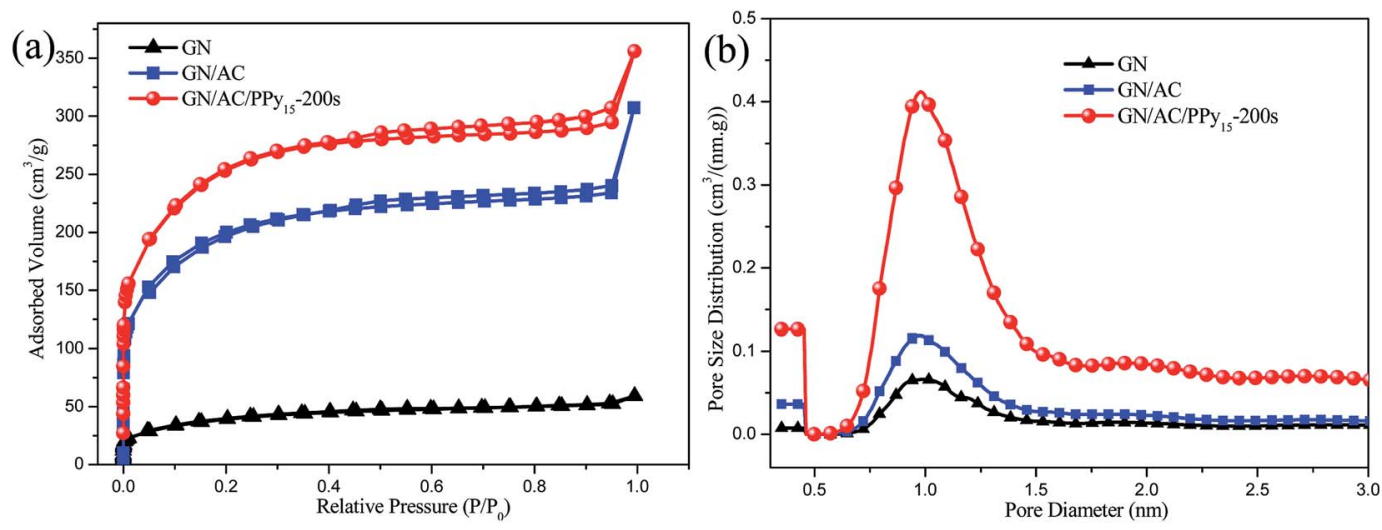

(c)

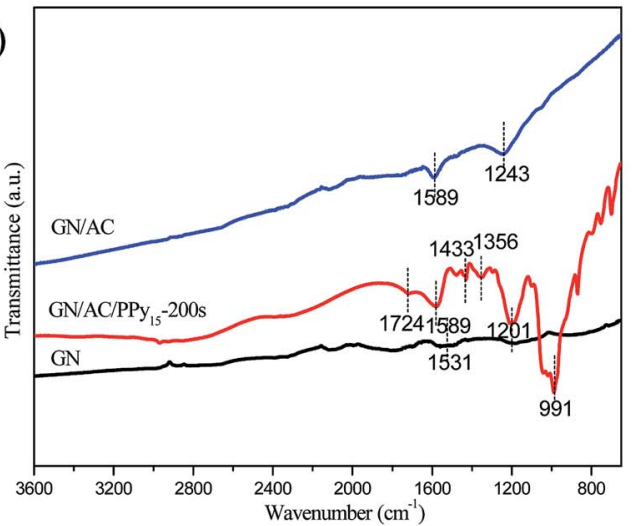

(d)

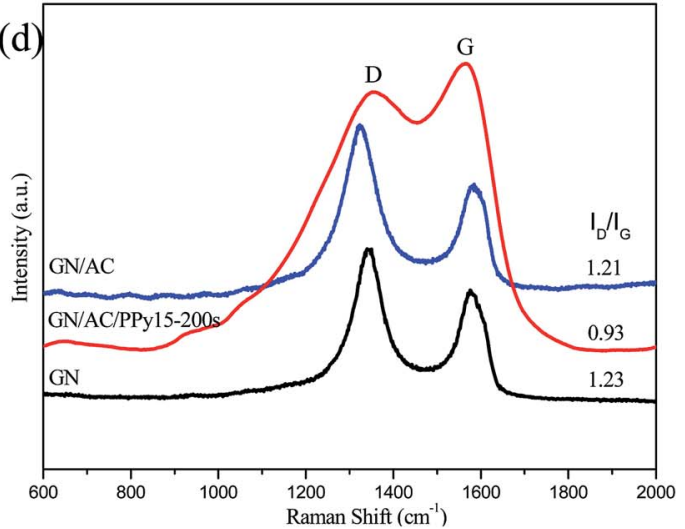

Fig. 3 (a) $\mathrm{N}_{2}$ adsorption/desorption isotherms (b) pore size distribution (c) FT-IR and (d) Raman spectra of GN, GN/AC and GN/AC/PPy $15-200 \mathrm{~s}$ electrode materials. 
Magnification image can be observed in the insert image in Fig. 2f, the PPy microspheres are stacked together, impeding the transportation of conductive ions.

The textural parameters of three different electrode materials were measured by Brunauer-Emmett-Teller (BET) surface area. The typical $\mathrm{N}_{2}$ adsorption/desorption isotherm at $77.35 \mathrm{~K}$ is shown in Fig. 3a, we can see that a typical sharp increase is appeared at a $P / P_{0}$ of 0.1 , which is the characteristic of micropores of carbon-based material. ${ }^{35}$ In particular, the composites of GN/AC and GN/AC/PPy ${ }_{15}-200 \mathrm{~s}$ have a significant increase of the adsorbed volume. ${ }^{37}$ The adsorption capacity significantly improves with the increase of the incorporation of AC and PPy. These results suggest that the composites promote the development of micro porosity and increase the specific surface area. The pore size distributions of all samples are shown in Fig. 3b. All electrode materials are dominated by the micro size with radius around 0.7 to $1.5 \mathrm{~nm}$, which contribute to the improvement of specific capacitance. These results could be explained by synergistic effects of excellent mechanical flexibility GN sheets, high conductive ACs and pseudocapacitive PPy. Such a 3D GN/AC/PPy $15-200 \mathrm{~s}$ film electrode without any binders has a larger specific surface area, which can be used as flexible electrode directly.

For the structure measurement, the FTIR and Raman spectra of the GN, GN/AC and GN/AC/PPy $15-200 \mathrm{~s}$ electrode materials are shown in Fig. 3c and d, respectively. As shown in Fig. 3c, the spectrum of the pure GN film has a slight fluctuation with a few minor peaks, indicating that graphene oxide is almost completely chemically reduced. The broad peaks observed at $1531 \mathrm{~cm}^{-1}$ and $1201 \mathrm{~cm}^{-1}$ represent the $\mathrm{C}-\mathrm{C}$ backbone stretching and $\mathrm{C}-\mathrm{OH}$ stretching vibration, respectively. ${ }^{38}$ The characteristic peaks appear in the spectra of GN/AC composite film at $1589 \mathrm{~cm}^{-1}$ and $1243 \mathrm{~cm}^{-1}$ are attributed to $\mathrm{C}=\mathrm{C}$ and $\mathrm{C}-$ O- stretching vibration, respectively. As respected, in the spectra of GN/AC/PPy $15-200 \mathrm{~s}$, the peaks at 1724, 1589, 1433, 1356, 1201 and $991 \mathrm{~cm}^{-1}$ are associated with the $\mathrm{C}=\mathrm{O}, \mathrm{C}=\mathrm{C}$, $\mathrm{C}-\mathrm{N}$ stretching vibration, $\mathrm{C}-\mathrm{N}$ in-plane deformation, and $\mathrm{C}-\mathrm{H}$ deformation vibration in the pyrrole ring, respectively, ${ }^{19}$ which indicated that the PPy successfully deposited onto the surface of GN/AC film via electrochemical polymerization method. Fig. 3d shows two prominent peaks located at $\sim 1343$ and $\sim 1575 \mathrm{~cm}^{-1}$, corresponding to the $\mathrm{D}$ and $\mathrm{G}$ bands of graphite, respectively.
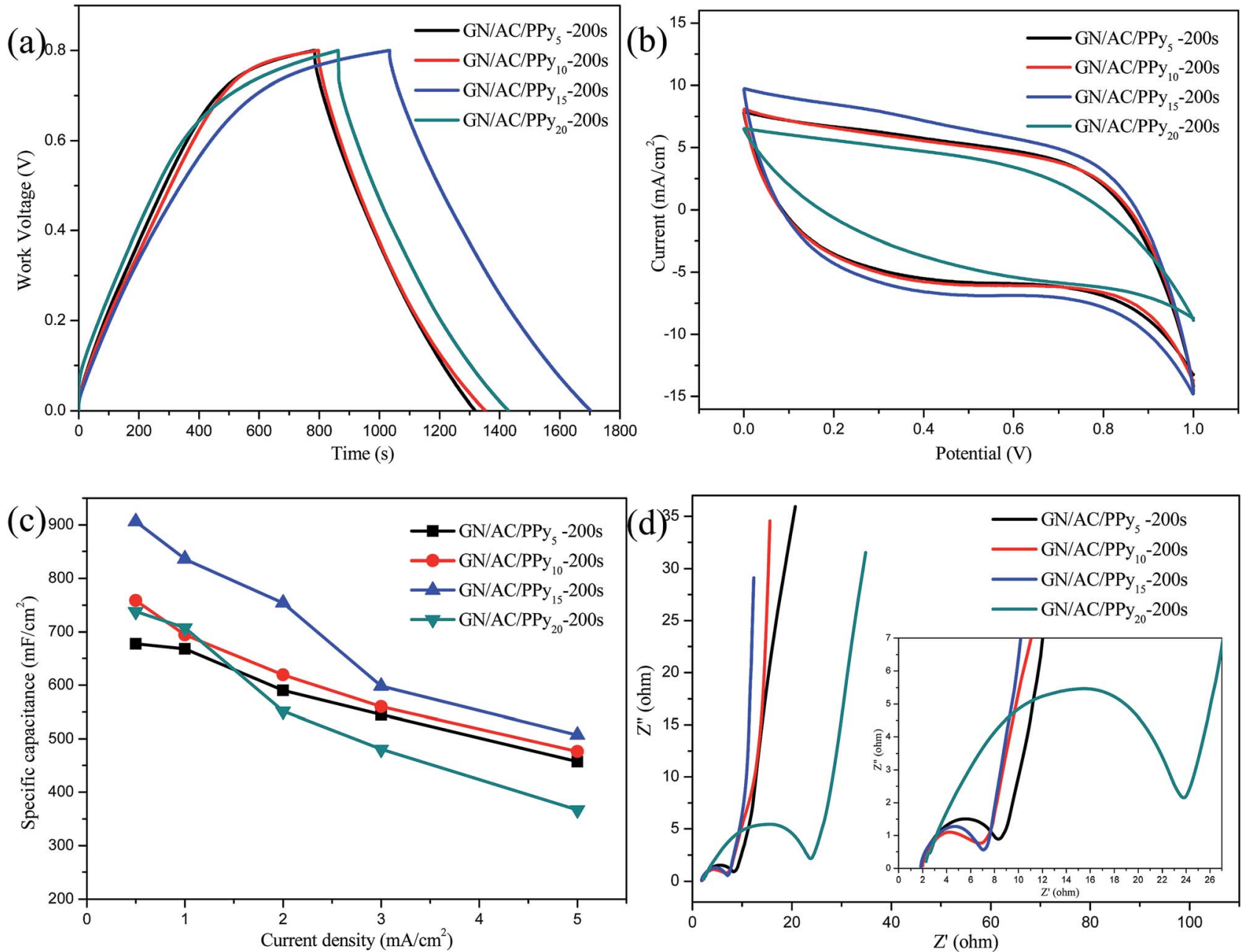

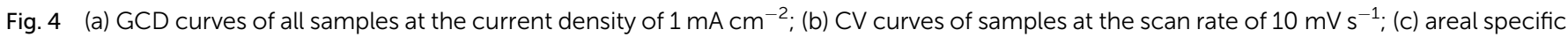
capacitances of all samples at different current densities; (d) Nyquist plot of all samples. 
The Raman spectra of GN/AC/PPy $15-200$ s exhibit two characteristic bands at 1355 and $1567 \mathrm{~cm}^{-1}$ due to the ring-stretching mode and the stretching of the $\pi$ conjugated structure of PPy, respectively. Moreover, the slightly peak at $931 \mathrm{~cm}^{-1}$ corresponds the out-of-plane $\mathrm{C}-\mathrm{H}$ deformation. ${ }^{39,40}$ The $\mathrm{D} / \mathrm{G}$ band intensity ratio $\left(I_{\mathrm{D}} / I_{\mathrm{G}}\right)$ expresses the atomic ratio of $\mathrm{sp}^{3} / \mathrm{sp}^{2}$ hybridized carbons, which reflects the extent of disordered graphite. ${ }^{\mathbf{4 1 , 4 2}}$ Compared with those intensity ratios $\left(I_{\mathrm{D}} / I_{\mathrm{G}}\right)$ of GN (1.23) and GN/AC (1.21), the decreased ratio of $I_{\mathrm{D}} / I_{\mathrm{G}}(0.93)$ in the Raman spectrum of GN/AC/PPy ${ }_{15}-200 \mathrm{~s}$ suggests the presence of strong interactions among GN, AC and PPy in this ternary composite, which makes the film electrodes achieve a good combination and excellent mechanical flexibility.

\subsection{Exploration of different deposition current densities}

Electrochemical performances of GN/AC/PPy as electrode materials were estimated under different disposition current densities. Fig. 4a shows GCD curves of all samples with a work voltage of $0-0.8 \mathrm{~V}$ at the current density of $1 \mathrm{~mA} \mathrm{~cm}{ }^{-2}$. It can be clearly seen that $\mathrm{GN} / \mathrm{AC} / \mathrm{PPy}_{15}-200 \mathrm{~s}$ electrode exhibits the largest charging/discharging time span, suggesting large specific capacitance. Also can be seen in Fig. 4b, CV curves of all samples with a potential of $0-1.0 \mathrm{~V}$ at the same scan rate of $10 \mathrm{mV} \mathrm{cm}{ }^{-2}$ show an early rectangular in shape, and GN/AC/ $\mathrm{PPy}_{15}-200 \mathrm{~s}$ electrode has the largest enclosed area. Furthermore, the areal specific capacitances $\left(C_{\mathrm{s}}\right)$ were calculated from GCD measurements using $C_{\mathrm{s}}=I \Delta t /(S \Delta V)$ in Fig. $4 \mathrm{c}$. It can be found that the areal specific capacitances of $\mathrm{GN} / \mathrm{AC} / \mathrm{PPy}_{15}-200 \mathrm{~s}$ electrode are 906, 836, 754, 560 and $458 \mathrm{mF} \mathrm{cm}^{-2}$ at current densities of $0.5,1,2,3$ and $5 \mathrm{~mA} \mathrm{~cm}{ }^{-2}$, respectively. These excellent electrochemical performances can be likely attributed to both $3 \mathrm{D}$ porous GN/AC flexible substrate and electrodeposition of coral-like PPy. The coral-like PPy can enlarge specific surface area and improve electronic conductivity. Fig. 4d depicts the Nyquist plot starts from the $Z^{\prime}$-axis and progresses almost vertically to the $Z^{\prime \prime}$-axis at the low frequency, indicating that the ideal capacitive characteristics of all electrodes. ${ }^{43}$ Moreover, GN/AC/PPy $15-200 \mathrm{~s}$ is the closest to the $Z^{\prime \prime}$ axis, further demonstrating that $\mathrm{GN} / \mathrm{AC} / \mathrm{PPy}_{15}-200 \mathrm{~s}$ has the best capacitive property. The measured impedance spectra are analyzed according to the semicircle intercepts of $Z^{\prime}$-axis (the inset of Fig. 4d). The resistances of the GN/AC/PPy $-200 \mathrm{~s}, \mathrm{GN} /$ $\mathrm{AC} / \mathrm{PPy}_{10}-200 \mathrm{~s}, \mathrm{GN} / \mathrm{AC} / \mathrm{PPy}_{15}-200 \mathrm{~s}$ and $\mathrm{GN} / \mathrm{AC} / \mathrm{PPy}_{20}-200 \mathrm{~s}$
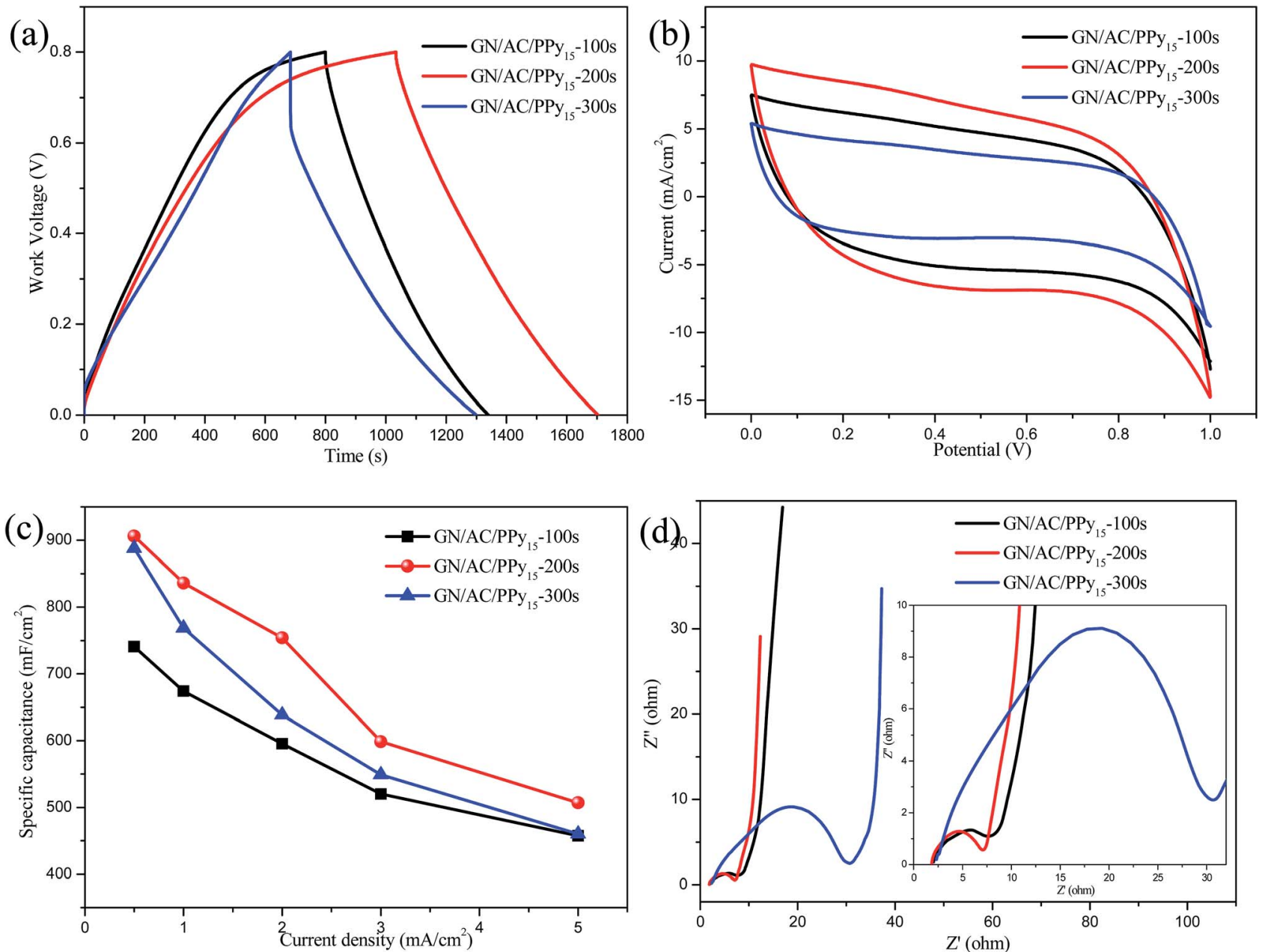

Fig. 5 (a) GCD curves of all samples at the current density of $1 \mathrm{~mA} \mathrm{~cm}^{-2}$; (b) CV curves of samples at the scan rate of $10 \mathrm{mV} \mathrm{s}$; (c) areal specific capacitances of all samples at different current densities; (d) Nyquist plot of all samples. 
electrode materials are $7.74,4.44,5.67$ and $26.86 \Omega$, respectively. The $\mathrm{GN} / \mathrm{AC} / \mathrm{PPy}_{20}-200 \mathrm{~s}$ electrode material has a large resistance, which mainly due to that high deposition current density is not conducive to longitudinal growth of PPy and easy to case a dense layer on GN/AC film. Therefore the selected deposition current density hereafter is $15 \mathrm{~mA} \mathrm{~cm}{ }^{-2}$.

\subsection{Exploration of different deposition times}

In order to explore the best electro-deposition conditions, the different deposition times were further evaluated at the deposition current density of $15 \mathrm{~mA} \mathrm{~cm}^{-2}$. As demonstrated in Fig. 5a, GN/AC/PPy $15-200 \mathrm{~s}$ has the longest time span. It also can
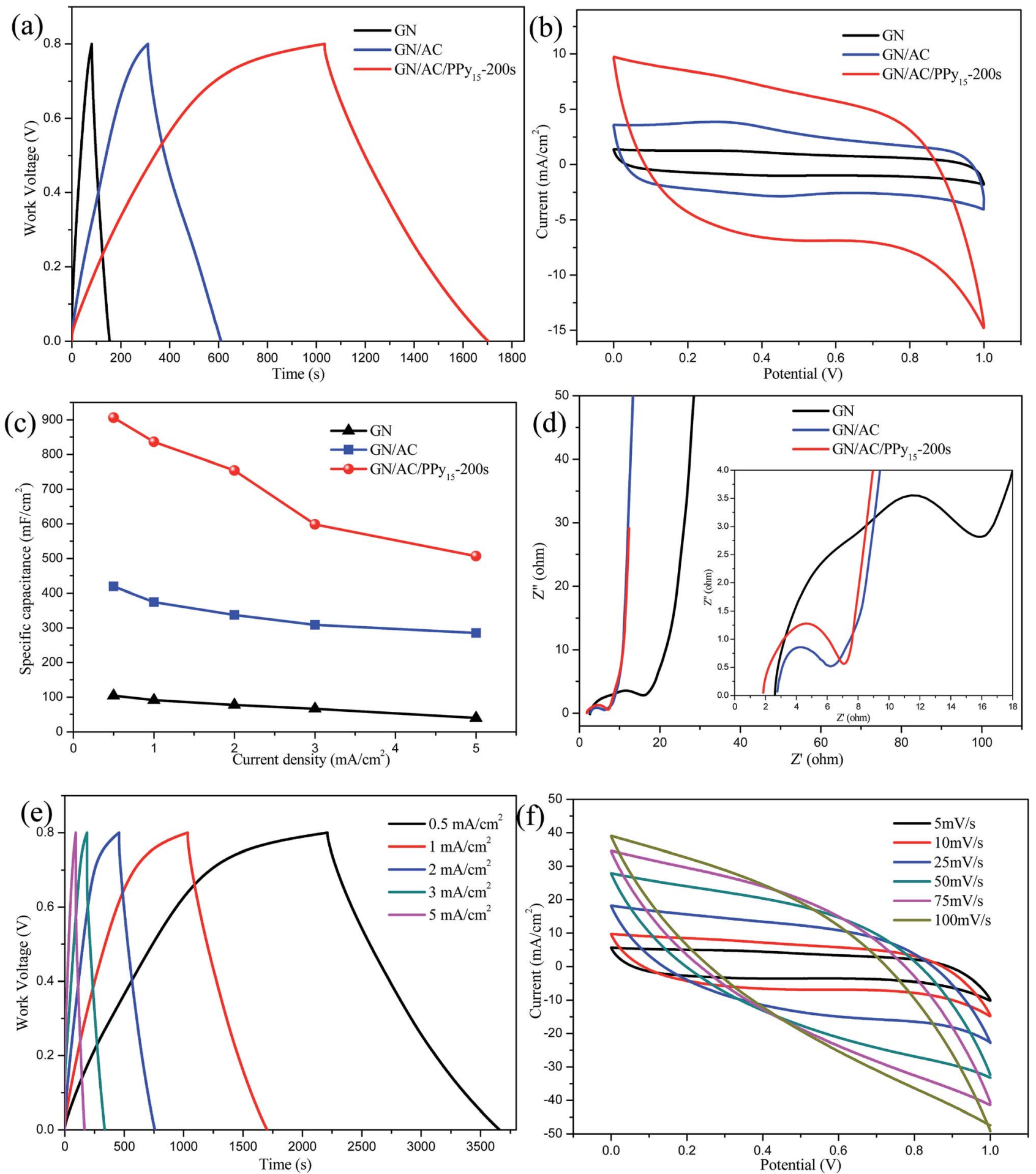

Fig. 6 (a) GCD curves of various electrode materials at the current density of $1 \mathrm{~mA} \mathrm{~cm}^{-2}$; (b) CV curves of various electrode materials at the scan rate of $10 \mathrm{mV} \mathrm{s}^{-1}$; (c) areal specific capacitances of various electrode materials at different current densities; (d) Nyquist plot of various electrode materials; (e) GCD curves of GN/AC/PPy $y_{15}-200 \mathrm{~s}$ at different current densities; (f) CV curves of GN/AC/PPy $15-200 \mathrm{~s}$ at different scan rates. 
be seen in Fig. 5b, influence of the deposition amount of PPy on $\mathrm{CV}$ curves, the GN/AC/PPy $15-200 \mathrm{~s}$ electrode material is greater than $\mathrm{GN} / \mathrm{AC} / \mathrm{PPy}_{15}-100 \mathrm{~s}$ and $\mathrm{GN} / \mathrm{AC} / \mathrm{PPy}_{15}-300 \mathrm{~s}$, respectively. It confirms that the different deposition times affect the morphology of electrode materials and further influence their electrochemical performance. The detailed values of areal specific capacitances $C_{\mathrm{s}}$ were calculated from GCD curves. As shown in Fig. 5c, the $C_{\mathrm{s}}$ values of GN/AC/PPy $15-100 \mathrm{~s}$, GN/AC/ $\mathrm{PPy}_{15}-200 \mathrm{~s}$ and $\mathrm{GN} / \mathrm{AC} / \mathrm{PPy}_{15}-300 \mathrm{~s}$ were 741,906 and $888 \mathrm{mF}$ $\mathrm{cm}^{-2}$ at a current density of $0.5 \mathrm{~mA} \mathrm{~cm}{ }^{-2}$, respectively. Additionally, upon increasing the current density to $5 \mathrm{~mA} \mathrm{~cm}{ }^{-2}$, the specific capacitance of $\mathrm{GN} / \mathrm{AC} / \mathrm{PPy}_{15}-200 \mathrm{~s}$ retained about $56 \%$ of its original value, indicating a good rate capability. However, for $\mathrm{GN} / \mathrm{AC} / \mathrm{PPy}_{15}-300 \mathrm{~s}$, only $52 \%$ of the capacitance retained when the current density up to $5 \mathrm{~mA} \mathrm{~cm}{ }^{-2}$. The electrochemical impedance spectroscopy (EIS) analysis were shown in Fig. 5d, the nearly vertical lines of all samples indicate a pure capacitive behavior and low diffusion resistance of ions in the structure of the electrode materials at low frequencies. ${ }^{\mathbf{4 4 , 4 5}}$ The resistance values of $\mathrm{GN} / \mathrm{AC} / \mathrm{PPy}_{15}-100 \mathrm{~s}, \mathrm{GN} / \mathrm{AC} / \mathrm{PPy}_{15}-200 \mathrm{~s}$ and $\mathrm{GN} / \mathrm{AC} /$ $\mathrm{PPy}_{15}-300 \mathrm{~s}$ were estimated to be 7.76, 5.67 and $33.93 \Omega$, respectively. GN/AC/PPy $15-300$ s electrodes present a higher resistance than others due to long deposition time caused the agglomeration of PPy microspheres. These results obtained by electrochemical impedance spectroscopy are in consisted with the above analysis. So the optimal deposition time is $200 \mathrm{~s}$.

\subsection{Comparison of electrode materials}

To further evaluate the electrochemical performance, three different electrode materials were compared. Fig. 6a illustrates the GCD curves of GN, GN/AC and GN/AC/PPy ${ }_{15}-200$ s electrode materials collected at $1 \mathrm{~mA} \mathrm{~cm}{ }^{-2}$. The GCD curves of GN/AC/ $\mathrm{PPy}_{15}-200 \mathrm{~s}$ also show the longest discharge time span, reflecting an improvement of the areal specific capacitance that the amount of mass loading has a great positive influence on the electrochemical performance. Fig. $6 \mathrm{~b}$ further compares the $\mathrm{CV}$ curves at the scan rate of $10 \mathrm{mV} \mathrm{s}^{-1}$. The smallest area of the $\mathrm{CV}$ curves of pure GN electrode materials indicates its inferior capacitive performance. Compared with the pure GN, GN/AC/ $\mathrm{PPy}_{15}-200 \mathrm{~s}$ presents an enlarged area and a nearly rectangular shape, implying a large capacitance during charge-discharge process. Variations of different electrode materials are revealed at different current densities in Fig. 6c. The plots of areal specific capacitances shift upward with the increasing of the composites. ACs have broaden the interlayer spacing of GNs, forming a large surface area and high conductive film. The deposition of PPy with a mass-loading of $2.75 \mathrm{mg} \mathrm{cm}^{-2}$ further increases the conductivity of the electrode material. The highest $C_{\mathrm{s}}$ reaches $906 \mathrm{mF} \mathrm{cm}^{-2}$ with the corresponding mass specific capacitance of $178 \mathrm{~F} \mathrm{~g}^{-1}$. Evidently, the specific capacitance are much higher than other composites, such as CQDs/PPy $(315 \mathrm{mF}$ $\left.\mathrm{cm}^{-2}\right),{ }^{19} \mathrm{PPy} / \mathrm{GO}\left(152 \mathrm{mF} \mathrm{cm}{ }^{-2}\right),{ }^{38} \mathrm{PPy} /$ bacterial cellulose $(153 \mathrm{~F}$
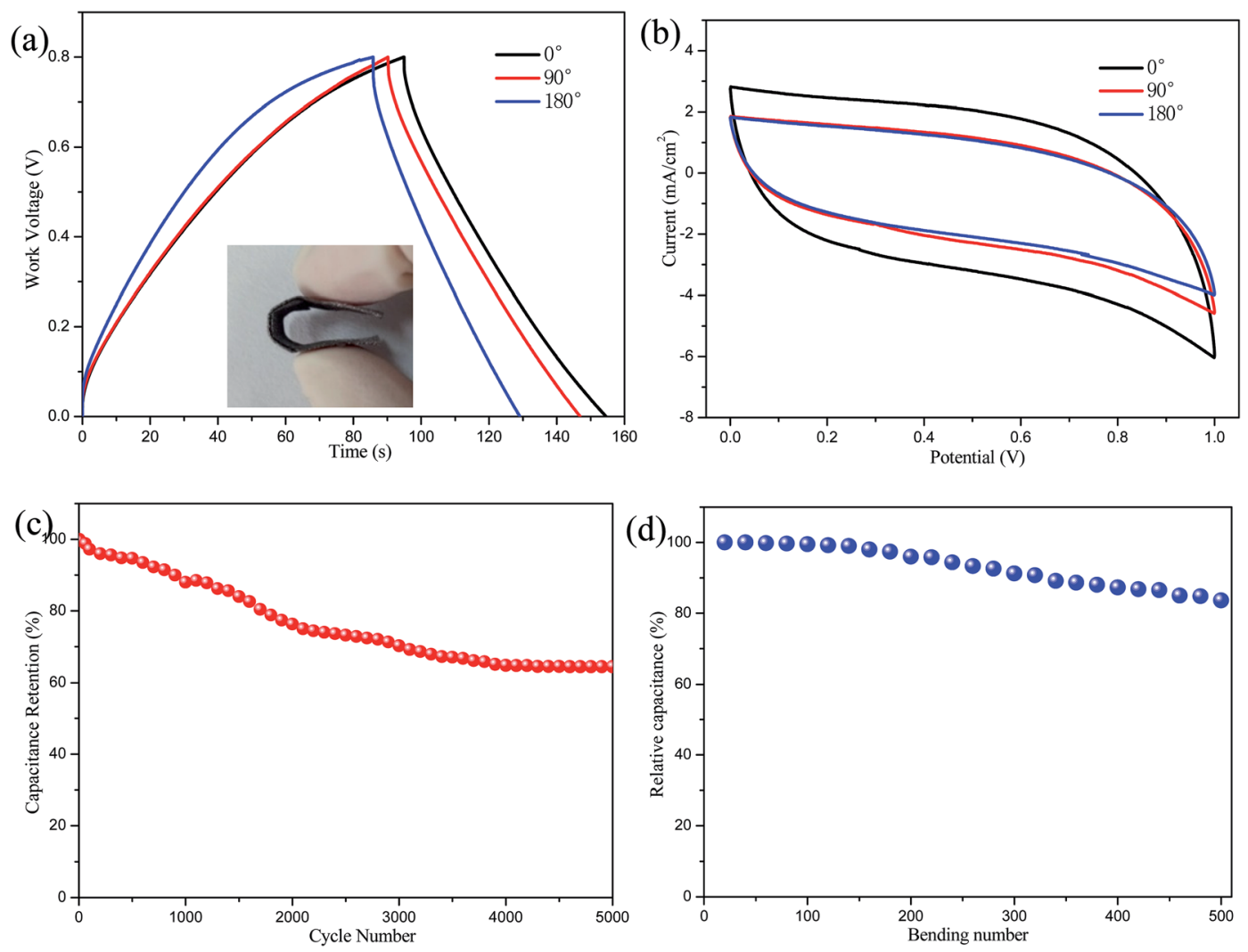

Fig. 7 (a) GCD curves of the flexible devices at $3 \mathrm{~mA} \mathrm{~cm}^{-2}$ under different bending angles; (b) $C V$ curves of the flexible devices at $10 \mathrm{mV} \mathrm{s}^{-1} \mathrm{under}$ different bending angles; (c) cycle performance of the GN/AC/PPy $15-200$ s electrode material; (d) the relative capacitance of the GN/AC/PPy ${ }_{15}-$ $200 \mathrm{~s}$ after different bending times. 
$\left.\mathrm{g}^{-1}\right) .{ }^{46}$ The Nyquist plot of three different electrode materials are shown in Fig. 6d, the pure GN presents a large contact interface resistance (14.09 $\Omega$ ) than others due to the compact layered structure and poor electrical conductivity of GN. Obviously, the conductivity of composites is enhanced because of the incorporation of $3 \mathrm{D}$ structures. From the insert image of Fig. 6d, the $\mathrm{GN} / \mathrm{AC} / \mathrm{PPy}_{15}-200 \mathrm{~s}$ electrode is the closest to vertical slopes in a low-frequency region, indicating a nearly ideal capacitive behavior. Thus, the ternary composites can achieve a synergistic effect and obtain the optimal electrochemical performance.

Furthermore, GCD curves of GN/AC/PPy ${ }_{15}-200 \mathrm{~s}$ at different current densities are shown in Fig. 6e. The GCD curves display an almost symmetric triangular shape with a small voltage drop, demonstrating a good capacitive property. Besides, Fig. $6 \mathrm{f}$ shows the CV curves collected at different scan rates in the voltage window of $1.0 \mathrm{~V}$, which exhibit a quasi-rectangular shape corresponding to a good electrochemical reversibility.

\subsection{Assembly of flexible supercapacitor}

Although the electrochemical performances measured in a three-electrode system are generally convenient and superior to those estimated in a two-electrode cell configurations, the two-electrode system is believed to approach more closely to the real applications of supercapacitors. Thus, a flexible symmetric supercapacitor was assembled by the $\mathrm{GN} / \mathrm{AC} / \mathrm{PPy}_{15}-200 \mathrm{~s}$ electrode materials. A two-electrode cell configuration was used to evaluate the capacitance performances. As can be seen from Fig. 7a and b, GCD curves and CV curves only change slightly when the bending angles of the flexible device varied from $0^{\circ}$ to $180^{\circ}$, demonstrating the electrodes have negligible influence on folding or bending. Moreover, the calculated volumetric specific capacitance of the symmetric supercapacitor changes from 1.86 $\mathrm{F} \mathrm{cm}^{-3}$ to $1.35 \mathrm{~F} \mathrm{~cm}^{-3}$ at a current density of $3 \mathrm{~mA} \mathrm{~cm}^{-2}$. There is about $27 \%$ fading for the specific capacitance when bended to $180^{\circ}$. For practical application, the cycling stability and mechanical flexibility are conducted. The cycle life test over 5000 cycles for $\mathrm{GN} / \mathrm{AC} / \mathrm{PPy}_{15}-200 \mathrm{~s}$ electrode is conducted by repeating GCD tests at the current density of $3 \mathrm{~mA} \mathrm{~cm}{ }^{-2}$. As shown in Fig. 7c, the GN/AC/PPy ${ }_{15}-200$ s electrode displays a good cyclic stability with $64.4 \%$ capacitance retention of the initial capacitance after 5000 cycles. To better clarify the mechanical flexibility of the flexible electrode, the relative capacitance of the GN/AC/PPy $15-200 \mathrm{~s}$ electrode after 500 bending cycles is shown in Fig. $7 d$. Fatigue test reveals that the specific capacitance of the flexible electrode maintained at $83.6 \%$ of the original value after 500 stretching-bending cycles.

\section{Conclusions}

In this study, furniture waste fiberboards were used to produce ACs, the 2D GN sheets were used as an ideal adhesive and supporter for ACs, forming a flexible and free-standing GN/AC composite film. The GN/AC film was adopted as a flexible substrate to support PPy nanoparticles, the GN/AC/PPy composites were synthesized via anodic constant current deposition method and designed by different deposition current densities and deposition times. The coral-like PPy tightly adhere to the surface of GN/AC composite film. The asfabricated GN/AC/PPy $15-200$ s composite electrode exhibits a maximum areal specific capacitance of $906 \mathrm{mF} \mathrm{cm}^{-2}$ with PPy loading mass of $2.75 \mathrm{mg} \mathrm{cm}^{-2}$ (specific capacitance of $178 \mathrm{~F} \mathrm{~g}^{-1}$ ) at a current density of $0.5 \mathrm{~mA} \mathrm{~cm}{ }^{-2}$, which is around 8.7 times of that of pure GN (104 $\left.\mathrm{mF} \mathrm{cm}^{-2}\right)$. Furthermore, a flexible supercapacitor was assembled and tested under different bending angles, indicating the device could accommodate the mechanical bending. The capacitance retention of electrode materials still remained at $64.4 \%$ after 5000 cycles at a higher current density of $3 \mathrm{~mA} \mathrm{~cm}{ }^{-2}$. Moreover, $83.6 \%$ of the capacitance was retained after 500 stretching-bending cycles. Overall, these results well demonstrated that our flexible, free-standing and binder-free $\mathrm{GN} / \mathrm{AC} / \mathrm{PPy}_{15}-200 \mathrm{~s}$ electrode is a promising candidate in wearable and portable electronic applications.

\section{Acknowledgements}

This work greatly thanked to the support of the Fundamental Research Funds for the Central Universities (No. 2016ZCQ01).

\section{References}

1 J. R. Miller, Valuing reversible energy storage, Science, 2012, 335, 1312-1313.

2 M. H. Yu, Y. F. Zhang, Y. X. Zeng, M. S. Balogum, K. C. Mai, Z. S. Zhang, X. H. Lu and Y. X. Tong, Water surface assisted synthesis of large-scale carbon nanotube film for highperformance and stretchable supercapacitors, Adv. Mater., 2014, 26, 4724-4729.

3 J. Zhu, Y. Xu, Y. Zhang, T. Feng, J. Wang, S. Mao and L. Xiong, Porous and high electronic conductivity nitrogendoped nano-sheet carbon derived from polypyrrole for high-power supercapacitors, Carbon, 2016, 107, 638-645.

4 P. Simon and Y. Gogotsi, Materials for electrochemical capacitors, Nat. Mater., 2008, 7, 845-854.

5 F. Béguin, V. Presser, A. Balducci and E. Frackowiak, Carbons and Electrolytes for Advanced Supercapacitors, Adv. Mater., 2014, 26, 2219-2251.

6 M. F. El-Kady, V. Strong, S. Dubin and R. B. Kaner, Laser scribing of high-performance and flexible graphene-based electrochemical capacitors, Science, 2012, 335, 1326-1330.

7 C. Lee, X. Wei, J. W. Kysar and J. Hone, Measurement of the elastic properties and intrinsic strength of monolayer graphene, Science, 2008, 321, 385-388.

8 L. Yuan, B. Yao, B. Hu, K. Huo, W. Chen and J. Zhou, Polypyrrole-coated paper for flexible solid-state energy storage, Energy Environ. Sci., 2012, 6, 470-476.

9 L. Liu, Z. Niu, L. Zhang, W. Zhou, X. Chen and S. Xie, Nanostructured graphene composite papers for highly flexible and foldable supercapacitors, Adv. Mater., 2014, 26, 4855-4862.

10 T. A. Skotheim and J. R. Reynolds, in Handbook of Conducting Polymers, CRC, New York, 2007.

11 Y. S. Lim, Y. P. Tan, H. N. Lim, W. T. Tan, M. A. Mahnaz, Z. A. Talib, N. M. Huang, A. Kassim and M. A. Yarmo, 
Polypyrrole/graphene composite films synthesized via potentiostatic deposition, J. Appl. Polym. Sci., 2013, 128, 224-229.

12 Y. Huang, J. Y. Tao, W. J. Meng, M. S. Zhu, Y. Huang, Y. Q. Fu, Y. H. Gao and C. Y. Zhi, Super-high rate stretchable polypyrrole-based supercapacitors with excellent cycling stability, Nano Energy, 2015, 11, 518-525.

13 A. Liu, C. Li, H. Bai and G. Shi, Electrochemical deposition of polypyrrole/sulfonated graphene composite films, J. Phys. Chem. C, 2010, 114, 22783-22789.

14 J. Zhang, Y. Yu, L. Liu and Y. Wu, Graphene-hollow PPy sphere 3D-nanoarchitecture with enhanced electrochemical performance, Nanoscale, 2013, 5, 30523057.

15 H. J. Tang, J. Y. Wang, H. J. Yin, H. J. Zhao, D. Wang and Z. Y. Tang, Growth of polypyrrole ultrathin films on $\mathrm{MoS}_{2}$ monolayers as high-performance supercapacitor electrodes, Adv. Mater., 2015, 27, 1117-1123.

16 Z. Q. Niu, H. B. Dong, B. W. Zhu, J. Z. Li, H. H. Hng, W. Y. Zhou, X. D. Chen and S. S. Xie, Highly stretchable, integrated supercapacitors based on single-walled carbon nanotube films with continuous reticulate architecture, Adv. Mater., 2013, 25, 1058-1064.

17 L. B. Hu, M. Pasta, F. L. Mantia, L. F. Cui, S. Jeong, H. D. Deshazer, J. W. Choi, S. M. Han and Y. Cui, Stretchable, porous, and conductive energy textiles, Nano Lett., 2010, 10, 708-714.

18 X. Zuo, Y. Zhang, L. Si, B. Zhou, B. Zhao, L. Zhu and X. Jiang, One-step electrochemical preparation of sulfonated graphene/polypyrrole composite and its application to supercapacitor, J. Alloys Compd., 2016, 688, 140-148.

19 X. Jian, H. Yang, J. Li, E. Zhang, L. Cao and Z. Liang, Flexible all-solid-state high-performance supercapacitor based on electrochemically synthesized carbon quantum dots/ polypyrrole composite electrode, Electrochim. Acta, 2017, 228, 483-493.

20 J. Yu, J. Wu, H. Wang, A. Zhou, C. Huang, H. Bai and L. Li, Metallic fabrics as the current collector for high-performance graphene-based flexible solid-state supercapacitor, ACS Appl. Mater. Interfaces, 2016, 8, 4724-4729.

21 R. B. Pujari, A. C. Lokhande, A. A. Yadav, J. H. Kim and C. D. Lokhande, Synthesis of MnS microfibers for high performance flexible supercapacitors, Mater. Des., 2016, 108, 510-517.

22 T. G. Yun, H. Bi, D. Y. Kim, S. Hyun and S. M. Han, Polypyrrole- $\mathrm{MnO}_{2}$-Coated Textile-Based Flexible-Stretchable Supercapacitor with High Electrochemical and Mechanical Reliability, ACS Appl. Mater. Interfaces, 2015, 7, 9228-9234.

23 Z. Pan, Y. Qiu, J. Yang, F. Ye, Y. Xu, X. Zhang, M. Liu and Y. Zhang, Ultra-endurance flexible all-solid-state asymmetric supercapacitors based on three-dimensionally coated $\mathrm{MnO}_{x}$, nanosheets on nanoporous current collectors, Nano Energy, 2016, 26, 610-619.

24 A. Ramadoss, B. Saravanakumar and J. K. Sang, Thermally reduced graphene oxide-coated fabrics for flexible supercapacitors and self-powered systems, Nano Energy, 2015, 15, 587-597.
25 J. Zhang, X. Zhao, Z. Huang, T. Xu and Q. Zhang, Highperformance all-solid-state flexible supercapacitors based on manganese dioxide/carbon fibers, Carbon, 2016, 107, 844-851.

26 Y. Lv, L. Gan, M. Liu, W. Xiong, Z. Xu, D. Zhu and D. Wright, A self-template synthesis of hierarchical porous carbon foams based on banana peel for supercapacitor electrodes, J. Power Sources, 2012, 209, 152-157.

27 T. X. Shang, Y. M. Zhu and X. J. Jin, Preparation of disused composite panels-based activated carbon by microwave induced activation for high performance of electric doublelayer capacitors: microwave power effects, Sci. Adv. Mater., 2016, 8, 1101-1107.

28 Y. Chen, X. Zhang, H. Zhang, X. Sun, D. Zhang and Y. Ma, High-performance supercapacitors based on a grapheneactivated carbon composite prepared by chemical activation, RSC Adv., 2012, 2, 7747-7753.

29 C. Zheng, X. Zhou, H. Cao, G. Wang and Z. Liu, Synthesis of porous graphene/activated carbon composite with high packing density and large specific surface area for supercapacitor electrode material, J. Power Sources, 2014, 258, 290-296.

30 H. B. Feng, R. Cheng, X. Zhao, X. F. Duan and J. H. Li, A lowtemperature method to produce highly reduced graphene oxide, Nat. Commun., 2013, 4, 1539.

31 H. Tian, S. Ma, H. M. Zhao, C. Wu, J. Ge and D. Xie, Flexible electrostatic nanogenerator using graphene oxide film, Nanoscale, 2013, 5, 8951-8957.

32 L. Ma, R. Liu, H. Niu, M. Zhao and Y. Huang, Flexible and freestanding electrode based on polypyrrole/graphene/ bacterial cellulose paper for supercapacitor, Compos. Sci. Technol., 2016, 137, 87-93.

33 W. S. Hummers, R. E. Offeman, W. S. Hummers and R. E. Offeman, Preparation of graphitic oxide, J. Am. Chem. Soc., 1958, 80, 1339.

34 N. I. Kovtyukhova, P. J. Ollivier, B. R. Martin, T. E. Mallouk, S. A. Chizhik and E. V. Buzaneva, Layer-by-Layer Assembly of Ultrathin Composite Films from Micron-Sized Graphite Oxide Sheets and Polycations, Chem. Mater., 1999, 11, 771778.

35 T. X. Shang, R. Q. Ren, Y. M. Zhu and X. J. Jin, Oxygen- and nitrogen-co-doped activated carbon from waste particleboard for potential application in high-performance capacitance, Electrochim. Acta, 2015, 163, 32-40.

36 S. Park, J. An, I. Jung, R. D. Piner, S. J. An and X. Li, Colloidal suspensions of highly reduced graphene oxide in a wide variety of organic solvents, Nano Lett., 2009, 9, 1593-1597.

37 D. Prahas, Y. Kartika, N. Indraswati and S. Ismadji, Activated carbon from jackfruit peel waste by $\mathrm{H}_{3} \mathrm{PO}_{4}$, chemical activation: pore structure and surface chemistry characterization, Chem. Eng. J., 2008, 140, 32-42.

38 H. Zhou, G. Han, Y. Xiao, Y. Chang and H. J. Zhai, Facile preparation of polypyrrole/graphene oxide nanocomposites with large areal capacitance using electrochemical codeposition for supercapacitors, J. Power Sources, 2014, 263, 259-267. 
39 A. Liu, C. Li, H. Bai and G. Shi, Electrochemical deposition of polypyrrole/sulfonated graphene composite films, J. Phys. Chem. C, 2010, 114, 22783-22789.

40 Y. Zhao, J. Liu, Y. Hu, H. Cheng, C. Hu, C. Jiang, L. Jiang, A. Cao and L. Qu, Highly compression-tolerant supercapacitor based on polypyrrole-mediated graphene foam electrodes, Adv. Mater., 2013, 25, 591-595.

41 T. Qian, C. F. Yu, S. S. Wu and J. Shen, A facilely prepared polypyrrole-reduced graphene oxide composite with a crumpled surface for high performance supercapacitor electrodes, J. Mater. Chem. A, 2013, 1, 6539-6542.

42 Z. Zhang, K. Chi, F. Xiao and S. Wang, Advanced solid-state asymmetric supercapacitors based on 3D graphene/ $\mathrm{MnO}_{2}$ and graphene/polypyrrole hybrid architectures, J. Mater. Chem. A, 2015, 3, 12828-12835.

43 P. S. P. L. Taberna, P. Simon and J. F. Fauvarque, Electrochemical Characteristics and Impedance
Spectroscopy Studies of Carbon-Carbon Supercapacitors, J. Electrochem. Soc., 2003, 150, A292-A300.

44 X. Zhang, J. Wang, J. Liu, J. Wu, H. Chen and H. Bi, Design and preparation of a ternary composite of graphene oxide/ carbon dots/polypyrrole for supercapacitor application: importance and unique role of carbon dots, Carbon, 2017, 115, 134-146.

45 W. Yang, Z. Gao, J. Wang, B. Wang, Q. Liu, Z. Li, T. Manna, P. Yang, M. Zhang and L. Liu, Synthesis of reduced graphene nanosheet/urchine like manganese dioxide composite and high performance as supercapacitor electrode, Electrochim. Acta, 2012, 69, 112-119.

46 F. Wang, H. J. Kim, S. Park, C. D. Kee, S. J. Kim and I. K. Oh, Bendable and flexible supercapacitor based on polypyrrolecoated bacterial cellulose core-shell composite network, Compos. Sci. Technol., 2016, 128, 33-40. 